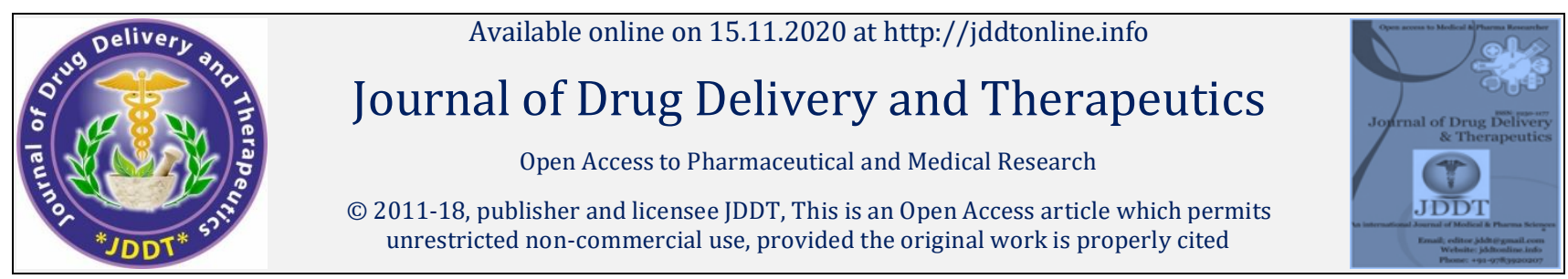

Open 1 Access

Research Article

\title{
Formulation and Evaluation of Microsponges Gel of Havan Ash for the Treatment of Acne
}

\author{
Sonali Syal*, Vinay Pandit, Amar Deep Ankalgi, C.P.S. Verma, M.S. Ashawat \\ Department of Pharmaceutics, Laureate Institute of Pharmacy, Kathog-Jawalamukhi, H.P, India
}

\begin{abstract}
The aim of this study was to develop the Microsponges containing Havan ash composed gel formulation for the treatment of Acne. Therefore, the topical formulation containing microsponges of Havan Ash will be formulated and evaluated. The preliminary investigation was carried out for the formulation of Havan ash loaded Microsponges by using quasi emulsion solvent diffusion method (MSF1-MSF6). In the preformulation studies of Havan ash the physical description and organoleptic properties, pH, acid insoluble ash, water-soluble ash, IR spectroscopy, identification test, rheological study, atomic absorption spectroscopy is also carried out. On the basis of particle size analysis of Microsponges, percentage yield formulation MSF5 containing Microsponges formula was selected for composition of topical gel formulation. Thus the different gel base formulation (G1-G3) using Carbopol-934 (1,1.5,2.0\%) was prepared by emulsification method. By considering all the relevant, physicochemical parameters, G2 gel base was selected for further loading of Havan ash containing Microsponges. The MSF5 formulation was loaded into the selected gel base G2 (1.5\%). Then the formulation and evaluation of Havan ash microsponges loaded gel was done. The formulation F3 has better results than other 4 formulations. F3 have its appearance silver colour, consistency very good, Grittiness -ve, homogeneity good, wash ability very good, pH 6.3, Spreadabilty (g.cm/sec) $14.4 \pm 0.77$ 7and viscosity (cps) $18251 \pm 50.12$, hav e good result of psychometric analysis. With the revealed results by different evaluation parameters, it is concluded that microsponges drug delivery system has become highly competitive and rapidly evolving technology and more research are carrying out to optimize cost-effectiveness and efficacy of the therapy.
\end{abstract}

Keywords: Havan ash, Antimicrobial, Microsponges, Acne vulgaris, Topical gel.

Article Info: Received 09 Sep 2020; $\quad$ Review Completed 20 Oct 2020; $\quad$ Accepted 28 Oct 2020; Available online 15 Nov 2020

Cite this article as:

Syal S, Pandit V, Ankalgi AD, Verma CPS, Ashawat MS, Formulation and Evaluation of Microsponges Gel of Havan Ash for the Treatment of Acne, Journal of Drug Delivery and Therapeutics. 2020; 10(6):74-85

http://dx.doi.org/10.22270/jddt.v10i6.4380

*Address for Correspondence:

Sonali Syal, Department of Pharmaceutics, Laureate Institute of Pharmacy, Kathog-Jawalamukhi, H.P, India

\section{INTRODUCTION}

According to Hindu mythology Bhasma or vibhuti is the sacred ash from the dhuni or fire where special wood, ghee, herbs, grains and other auspicious and purifying items are offered for worship along with mantras. Culturally, we attach a lot of importance to the holy ash on the forehead. Applying vibhuti or bhasma or the holy ash is a common practice in India. In older times RishiMuni, ancient scholars and physicians used to recommend Hawan for mental peace and well-being. Gayatri Mantra also tells that sughandhim (aroma, fragrance) puushtivardhanam (gives rise to good health). Om triambkum yajamahe, sughandhim puushtivardhanam, urvarukmev vandhanaat, mrityu mokshay mamritaat. ${ }^{1-4}$

Hawan is a scientific experiment in which special herbs (Hawan Samagri) are offered in the fire of medicinal woods ignited in a specially designed fire pit called agnikuñda. Hawan seems to be designed by the ancient scholars to fight with the diseases of the brain. Our metadata analysis demonstrates that the components of Hawan are having a number of volatile oils that are specifically useful for epilepsy through one or the other mechanism of action. Due to high temperature of fire the vapors of these oils enter into the central nervous system through nasal route. The routine of performing Hawan might keep the threshold value of the therapeutic components in the body and help in preventing epilepsy. 5

Hawana is one of the most important Vedic ritualistic sacrifices which involves lighting fire in a rectangular Homa Kunda. Hawan is an ancient ritual which is performed to purify the atmosphere and the environment. Hawan is also believed to help plants to acquire a protective coating against pests and diseases. Hawan Samagri is a collection of 
plant material for burning in a Hawan along with other herbal embodiments or sacrificial fire. These herbs have antibacterial, antiviral and many other therapeutic properties. When the Hawan Samagri burn, their smoke clears toxins and harmful micro-organisms from the environment. Since long back in our traditional treatise such Hawan ash had been used for various dermal disorder like, wound healing, eczema, scabies, as moisturising agent and skin protective antiacne, anti-wrinkle, sun protective agent etc. Hawan Ash have some medicinal properties like antibacterial, antiviral, antifungal, antimicrobial, anti-itching etc. It has antibacterial activity which used as an active ingredient for the treatment of Acne Vulgaris. ${ }^{6}$

From that traditionally method we get idea to formulate topical pharmaceutical dosages formcontaining hawan ash (vibhuti) for prevention of skin disorder.

During the past few years, interest in the development of Novel Drug Delivery Systems for existing drug molecules has been renewed. The development of a Novel Delivery System for existing drug molecules not only improves the drug's performance in terms of efficacy and safety but also improves patient compliance and overall therapeutic benefit to a significant extent.

When properly designed and developed for a particular drug, novel drug delivery system can overcome specific hurdles associated with conventional methods of delivery, e.g. drugs that undergo partial or complete degradation before reaching the site of action could be effectively delivered with improved bioavailability by using the novel concepts of timed, pulsatile, or targeted release. ${ }^{7}$

Time is the fastest runner and as we are running in the 21 " century, an era where the technology and research has enriched the quality of our life with the advancement in the pharmaceutical and medical science. This dedication has sorted out many health related problems. In today's life every person whether its man or woman dreamt of a flawless skin. Like other ailments, skin diseases are the most emphasized and burning topic in the researcher's mind. Here, we are focusing and dealing with Acne, the most common skin disease that occurs most commonly during adolescence, affecting more than $96 \%$ of teenagers, and frequently continues into adulthood.

Investigations and past research in the treatment of acne showed that the conventional administration of antimicrobials and antibiotics (creams, gels and lotions) are used to treat only mild to moderate form of acne but cannot be used in severe and nodulocystic form of acne. Additionally, the antibiotics and benzoyl peroxide nonspecifically reduce bacterial population on the skin, which imbalance the homeostasis and cause further complications such as promoting growth of antibiotic-resistant bacterial strains. Therefore, antibiotics are becoming less and less useful as resistant P.acnes are becoming more common. Acne return soon after the end of treatment-days later in the case of topical applications, and weeks later in the case of oral antibiotics. This shows that the conventional administration of drug sometimes proves to be insecure because of erratic response, overdosing and contrast monitoring. Therefore, it becomes a great responsibility on the shoulders of pharmacist to develop an effective dosage form enveloping the principle active moiety in treating the acne with minimum side-effects and maximum patient compliance. Currently, research is aimed at the development of drug delivery system with maximum therapeutic benefits for safe and effective management of the disease. 8
A Microsponge Delivery System (MDS) is patented, highly cross-linked, porous, polymeric microspheres that can entrap wide range of actives and then release them onto the skin over a time and in response to trigger. This system was employed for the improvement of performance of topically applied drugs. It is a unique technology for the controlled release of topical agents and consists of microporous beads, typically 10-25 microns in diameter, loaded with active agent. When Microsponge delivery system applied to the skin, the release of drug can be controlled through diffusion or other variety of triggers, including rubbing, moisture, $\mathrm{pH}$ friction, or ambient skin temperature. 9-13

Microsponge technology offers:

* Enhanced product performance.

* Extended release.

* Reduced irritation and hence improved

* Improved product elegancy.

* Oil control: Microsponge can absorb oil up to 6 times its weight without drying.

* Improved formulation flexibility.

* Improved thermal, physical, and chemical stability.

* Flexibility to develop novel product forms.

* Microsponge systems are non-irritating, nonmutagenic, non-allergenic and non-toxic.

\section{Properties of the Actives for the Entrapment into} Microsponges

- It should be either fully miscible in a monomer or capable of being made miscible by the addition of a small amount of a water-immiscible solvent.

- It should be water immiscible or at most only slightly soluble.

- It should be inert to monomers and should not increase the viscosity of the mixture during formulation.

- It should be stable when in contact with the polymerization catalyst and under conditions of polymerization.

- The spherical structure of the microsponges should not collapse.

\section{Acne Vulgaris}

Acne Vulgaris (commonly called acne) is a follicular skin disease that mainly affects the Pilosebaceous unit of face, neck, and trunk and is characterized by inflammatory (papules, pustules, nodules, and cysts) and noninflammatory lesions (Seborrhea and Comedones) and scarring. Acne may be of inflammatory or non-inflammatory forms. Although in many patients, acne can be limited to a couple of papules or Comedones, serious illness can lead to disfiguring scars on the face. Despite not being a lifethreatening disease, acne can have severe psychosocial consequences causing low self-esteem, social isolation, and depression. ${ }^{14}$

Acne, a multifarious chronic inflammatory state, is said to be happening within a pilosebaceous unit (PSU) including hair, hair follicles, sebaceous gland (SG) of the skin, characterized by non-inflammatory lesions blackheads, whiteheads and inflammatory Lesionspapules, Pustul, nobless, nodules, and cysts. Acne vulgaris is characterized by various clinical 
conditions such as scaly red skin (Seborrhea), erythematous papules and pustules, Comedones, nodules, deep pustules, and sometimes pimples [shown in figure 1]. 15 Acne is associated mostly with Propionibacterium acnes (P. acnes) which produces inflammation via release of extracellular enzymatic products like proteases, lipases, and hyaluronidases. About $94-95 \%$ of the pubertal population, $20-40 \%$ of adults and $<25 \%$ of women suffered from acne. Even after 25 years of age, women can suffer from is termed as adult female acne. Primarily four causes are critically responsible for the growth of acne lesion.

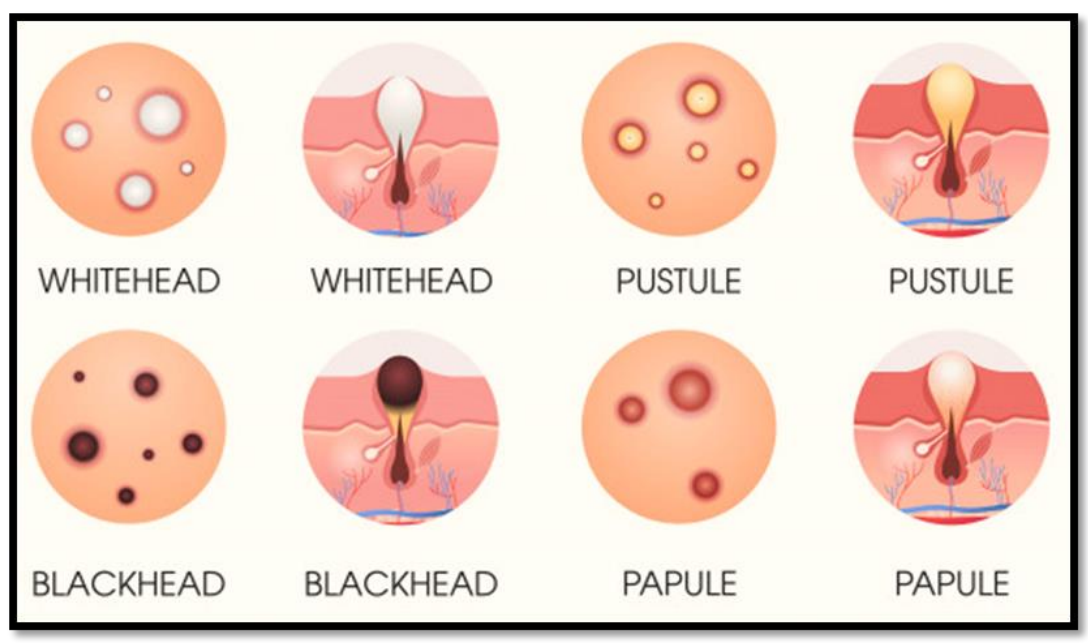

Figure 1: Different type of acne

The treatment of acne can be given by topical or systemic therapy. The topical therapies include antibiotics, antiinflammatory and Comedolytic agent, chelating agent, natural product 16-20.

Traditional herbal medicine has been used since ancient time in many parts of the world where access to formal and modern healthcare is limited 21. Traditional herbal medicines provide an interesting, largely unexplored source for new drug development 22. Medicinal plants have a long history and have been shown to possess less side effects. These herbs negligible the adverse effect as compared with modern medicines and become another important aspect to treat acne vulgaris. Upcoming years herbal therapies are gaining attention of academician, industrialist, cosmetician, researches, dermatologist and scientist for treatment of acne. Acne can be cured by herbs by both externally and internally. Topical treatment of herbs is first choice of customers as it is ease for application and it supresses the bitter taste of herbal formulation. Because herbs are safe, efficacious and the added advantage of multifunctionality, herbs are increasingly being used in mainstream cosmetic products, including acne- fighting compositions 23-24.

Microsponge can be prepared with two methods i.e. one step process (liquid-liquid polymerization method) and two-step process (quasi emulsion solvent diffusion method). Most common and feasible method used for preparation of microsponges is quasi emulsion solvent diffusion method.

\section{METHODS}

\section{Method of Preparation of Microsponge}

Microsponges of Havan Ash and Eudragit RL 100 was prepared by quasi-emulsion solvent diffusion method according to the formula given in table no 1 , the process involved formation of quasi-emulsion of two different phases i.e. internal phase and external phase similar to emulsions. Table no 2 gives the detailed information about the prepared formulations. $25-26$

1. Preparation of internal phase: the phase was consisted of drug (Havan Ash), polymer (Eudragit RL 100) and solvent (ethanol and dichloromethane in ratio 1:1). To prepare this phase, Eudragit RL 100 was dissolved in the mixture of solvents and then drug was further added to it and dissolved under sonication.

2. Preparation of external phase (aqueous phase): for the preparation of aqueous phase, weighed quantity of polyvinyl alcohol was taken and dissolved in $50 \mathrm{ml}$ of water in beaker.

3. Mixing: The internal organic phase was poured into the external aqueous phase by drop wise.

4. Stirring: The stirring was continued up to $6 \mathrm{hrs}$ till the insoluble, rigid microparticles i.e. microsponges is formed.

5. Filtration: The mixture was allowed to stir until the foam settled down and after the complete evaporation of dichloromethane the mixture was filtered with whatmann filter paper $(0.45 \mu \mathrm{m})$.

6. Drying: The microsponges were then dried in an air heated oven. $27-28$ 


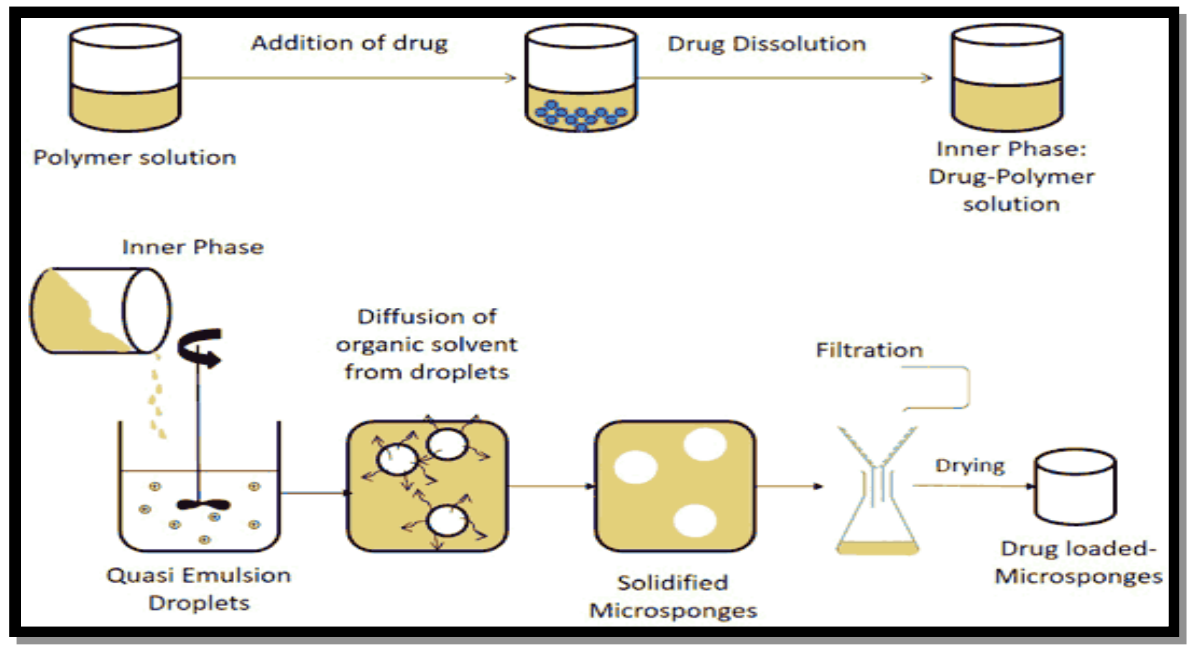

Figure 2: Preparation of Microsponge

Table 1: Formulation of Microsponges of Havan Ash

\begin{tabular}{|c|c|c|c|c|c|c|c|}
\hline Sr. No. & Ingredient (mg/ml/gm) & F1 & F2 & F3 & F4 & F5 & F6 \\
\hline $\mathbf{1 .}$ & $\begin{array}{c}\text { Havan ash: } \\
\text { Eudragit RL 100 }\end{array}$ & $1: 01$ & $1: 2$ & $1: 03$ & $1: 04$ & $1: 05$ & $1: 06$ \\
\hline $\mathbf{2 .}$ & Havan ash & 500 & 500 & 500 & 500 & 500 & 500 \\
\hline $\mathbf{3 .}$ & Eudragit RL 100 & 50 & 100 & 150 & 200 & 250 & 300 \\
\hline $\mathbf{4 .}$ & $\begin{array}{c}\text { Dicholromethane: } \\
\text { Ethanol (5ml) }\end{array}$ & $1: 1$ & $1: 1$ & $1: 1$ & $1: 1$ & $1: 1$ & $1: 1$ \\
\hline $\mathbf{5 .}$ & Polyvinyalcohol (mg) & 200 & 200 & 200 & 200 & 200 & 200 \\
\hline $\mathbf{6 .}$ & Distilled water (ml) & 200 & 200 & 200 & 200 & 200 & 200 \\
\hline
\end{tabular}

\section{Optimization of Microsponges}

\section{- Particle size analysis of Microsponges}

The particle size of the Microsponge was determined by optical microscopy and the microsponges were found to be uniform in size. The average particle size of all formulations ranges from $27.5 \mu \mathrm{m}$ to $43.9 \mu \mathrm{m}$.

\section{- Percentage yield}

It is calculated to know about the efficiency of any method, thus it helps in selection of appropriate method of production. After the preparation of formulations, the Practical yield was calculated as Microsponges recovered from each preparation in relation to the sum of starting material (Theoretical yield). It can be calculated using following formula.

Percentage yield $=\quad$ Practical yield $\times 100$ Theoretical yield (drug + polymer)
The Pharma Innovation Journal The loss of product was due to the formation of some agglomerates and polymer adherence to the container as a result of a viscous nature of slurry. It is calculated to know about the efficiency of any method, thus it helps in selection of appropriate method of production and in this experiment, it is revealed that with increase in polymer ratio the percent yield also increases.

\section{Formulation and Evaluation of Gel Base}

Formulation of gel base (100 g) was formulated by emulsification method (shown in table no.2). The appropriate quantity of carbopol 934 was soaked in water for a period of 2 hours. After soaking for 2 hours it was properly mixed with a help of glass rod. Carbopol was then neutralized with triethanolamine (TEA) with stirring. Methyl paraben and propyl paraben were added into the gel as a preservative. The gel was mixed with constant stirring followed by the magnetic stirrer to get a smooth gel. ${ }^{29}$

Table 2: Formulation of gel base

\begin{tabular}{|c|c|c|c|c|}
\hline \multirow{2}{*}{ Sr. No. } & Ingredient & \multicolumn{3}{|c|}{ Quantity (mg/ml) } \\
\cline { 2 - 5 } & Formulation code & G1 & G2 & G3 \\
\hline $\mathbf{1 .}$ & Carbopol 934 & $1 \%$ & $1.5 \%$ & $2 \%$ \\
\hline $\mathbf{2 .}$ & Glycrine (ml) & 2.5 & 2.5 & 2.5 \\
\hline $\mathbf{3 .}$ & Alcohol (ml) & 2 & 2 & 2 \\
\hline $\mathbf{4 .}$ & Methyl paraben (g) & 0.1 & 0.1 & 0.1 \\
\hline $\mathbf{5 .}$ & Triethanolamine (ml) & 2 & 2 & 2 \\
\hline $\mathbf{6 .}$ & Distilled water & q.s & q.s & q.s \\
\hline
\end{tabular}




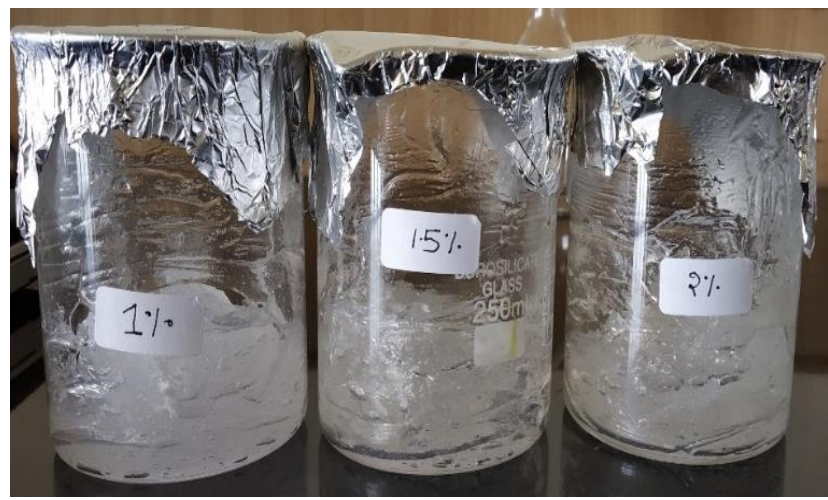

Figure 3- Different Type of Gel Base

\section{Evaluation of Gel Base}

The gel bases were evaluated for physical appearance, grittiness, $\mathrm{pH}$, spreadabilty and viscosity.

\section{- Physical appearance}

Gel base was evaluated visually for color, homogeneity and smoothness.

\section{- Grittiness}

A small amount of gel was taken and spread between two glass slides free from grease and was observed against diffused light to check for presence of foreign particle.

\section{- Determination of $\mathbf{p H}$}

The sample of gel $(5 \mathrm{~g})$ was weighed and transferred into a $100 \mathrm{ml}$ of beaker. The distilled water of $45 \mathrm{ml}$ was added to the beaker and maintained to $45^{\circ} \mathrm{C}$ with constant stirring using glass rod for 15 minute on a heating mantle. The solution was filtered and $\mathrm{pH}$ was measured using digital $\mathrm{pH}$ meter at $27^{\circ} \mathrm{C}$.

\section{- $\quad$ Spreadabilty}

Spreadabilty of gel was determined by the apparatus which consists of a wooden block, which is attached to a pulley at one end. Spreadabilty was measured on the basis of 'Slip' and 'Drag' characteristics of gel. A ground glass slide was fixed on the wooden block. All the sample (about $1 \mathrm{~g}$ ) were applied in between these two glass slides and they were pressed together so as to expel the air and to provide a uniform thickness of gel by placing $100 \mathrm{~g}$ of weight for 5 minutes. The top glass slide has the same dimension as that of the fixed ground slide. Therefore, a weight $(10 \mathrm{gm})$ was added to the pan and the top glass slide was subjected to pull with the help of string attached to the hook (Fig 4). The time in which the upper glass slide moves over the lower plate to cover a distance of $10 \mathrm{~cm}$ is noted. The spread ability (S) can be calculated using the formula. The following equation was used for the purpose:

$$
\mathrm{S}=\mathrm{M} \times \mathrm{L} / \mathrm{T}
$$

Where, $\mathrm{S}=$ spreadabilty $\quad \mathrm{M}=$ weight (gram)

$$
\mathrm{L}=\text { length }(\mathrm{cm}) \quad \mathrm{T}=\text { time (seconds/minutes) }
$$

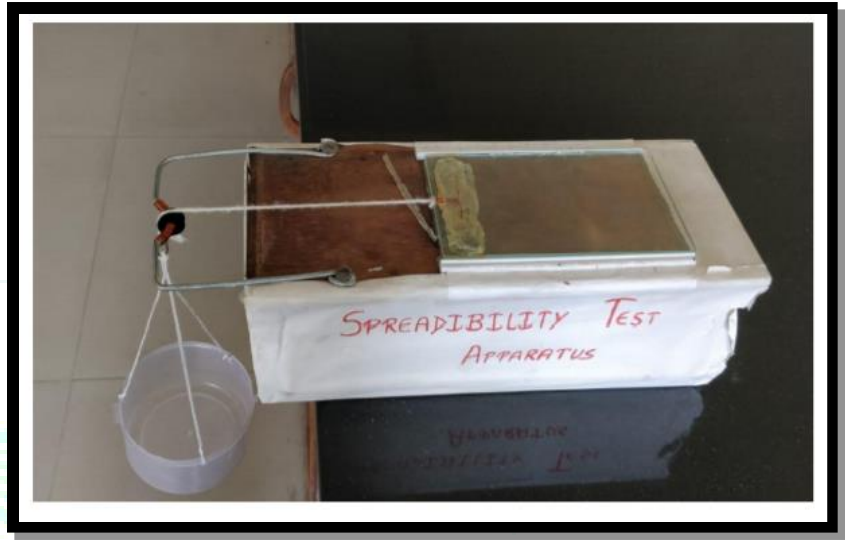

Figure 4: Fabricated spreadabilty apparatus

\section{- Determination of viscosity}

The gel base formulation was evaluated for viscosity (in cps) using Brookfield rheometer (Conc. and plate) (R/S Plus). The sample of 1 gram (maintained at $25 \pm 1^{\circ} \mathrm{C}$ ) was placed on the plate and conc. was rotated at $10 \mathrm{rpm}$.

\section{Formulation and Evaluation of Havan Ash Microsponges Loaded Gel Base}

Table 3: Formulation of Havan Ash Microsponges Loaded Gel Base

\begin{tabular}{|c|c|c|c|c|c|}
\hline Sr. No. & Ingredient & F1 & F2 & F3 & F4 \\
\hline $\mathbf{1 .}$ & Havan ash Microsponges & 550 & 650 & 750 & 850 \\
\hline $\mathbf{2 .}$ & Carbopol 934 & $1.5 \%$ & $1.5 \%$ & $1.5 \%$ & 1.5 \\
\hline $\mathbf{3 .}$ & Glycrine (ml) & 2.5 & 2.5 & 2.5 & 2.5 \\
\hline $\mathbf{4 .}$ & Alcohol (ml) & 2 & 2 & 2 & 2 \\
\hline $\mathbf{5 .}$ & Methyl paraben (g) & 0.1 & 0.1 & 0.1 & 0.1 \\
\hline $\mathbf{6 .}$ & Triethanolamine (ml) & 2 & 2 & 2 & 2 \\
\hline $\mathbf{7 .}$ & Distilled water & q.s & q.s & q.s & q.s \\
\hline
\end{tabular}




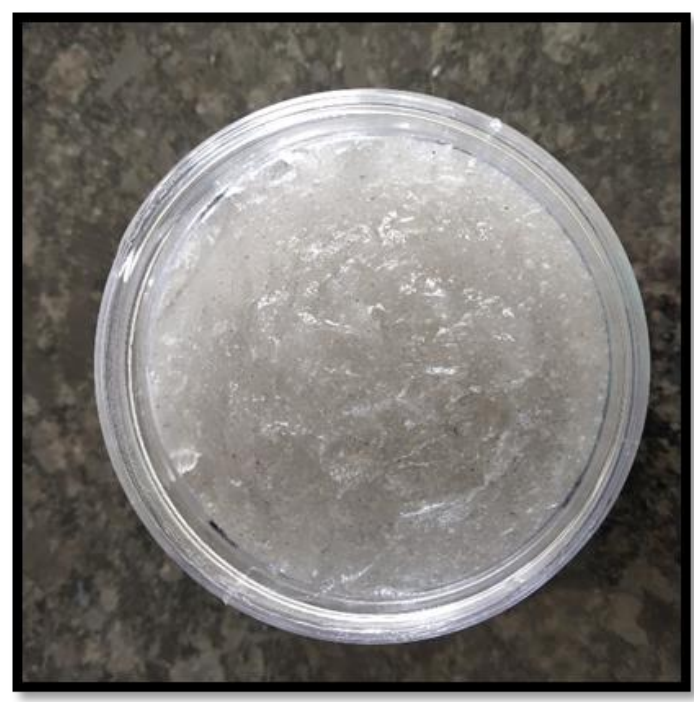

Figure 5: Havan Ash Microsponges Loaded Gel

\section{Evaluation of Havan Ash Microsponges Loaded Gel}

\section{- Determination of Organoleptic Characteristics.}

All blank formulations (i.e., formulations without any active ingredients or preservatives) and drug-loaded formulations were tested for physical appearance, colour, texture, phase separation, and homogeneity. These characteristics were evaluated by visual observation. Homogeneity and texture were tested by pressing a small quantity of the formulated cream and gels between the thumb and index finger. The consistency of the formulations and presence of coarse particles were used to evaluate the texture and homogeneity of the formulations. Immediate skin feel (including stiffness, grittiness, and greasiness) was also evaluated.

\section{- Determination of $\mathrm{pH}$}

One gram of each formulation (including the blank, i.e., formulation without any active ingredients or preservatives, and drug-loaded formulation) was dispersed in $25 \mathrm{~mL}$ of distilled water, and the $\mathrm{pH}$ was determined using a $\mathrm{pH}$ meter.

\section{- Psychometric Evaluation}

Study design

This prospective study was conducted at the department of pharmaceutics, laureate institute of pharmacy kathog (H.P) as per the ethical guidelines. Twelve human volunteers $(6$ six females and six males in the average age group of, 20-24) were selected for this study by making three groups for read through the individual variation. All the subjects were tested exclusively using the prepared gel formulation coded as F1, F2, F3, F4 for the psychometric parameters according to Hedonic Scale values.

- Extremely liking:

- Between extremely liking and medium:

- Medium:

- Between medium and dislikes:

- Dislike:

Psychometric analysis includes: colour, odour, texture, wetness, gloss, stickiness, Slipperiness, firmness, Appearance, Rub-out, After-feel effect and Pick-up and also to observe the initial compliance and safety of the gel. An application site is having a $2 \mathrm{~cm} 2$ sample area. The study was conducted at $25^{\circ} \mathrm{C}$.

\section{- Wash ability}

Formulations were applied on the skin and then ease and extent of washing with water were checked manually.

\section{- Determination of spreadabilty}

Spreadabilty of gel was determined by the apparatus which consists of a wooden block, which is attached to a pulley at one end. Spreadabilty was measured on the basis of 'Slip' and 'Drag' characteristics of gel. A ground glass slide was fixed on the wooden block. All the samples (about 1g) were applied in between these two glass slides and they were pressed together so as to expel the air and to provide a uniform thickness of gel by placing $100 \mathrm{~g}$ of weight for 5 minutes. The top glass slide has the same dimension as that of the fixed ground slide. Therefore, a weight $(10 \mathrm{gm})$ was added to the pan and the top glass slide was subjected to pull with the help of string attached to the hook (Fig 8). The time in which the upper glass slide moves over the lower plate to cover a distance of $10 \mathrm{~cm}$ is noted. The spread ability (S) can be calculated using the formula The following equation was used for the purpose:

$$
\mathrm{S}=\mathrm{M} \times \mathrm{L} / \mathrm{T}
$$

Where, $\mathrm{S}=$ spreadabilty

$\mathrm{M}=$ weight (gram)

$\mathrm{L}=$ length $(\mathrm{cm})$

$\mathrm{T}=$ time (seconds/minutes)

\section{- Determination of viscosity}

The gel base formulation was evaluated for viscosity (in cps) using Brookfield rheometer (Conc. and plate) (R/S Plus). The sample of 1 gram (maintained at $25 \pm$ $1^{\circ} \mathrm{C}$ ) was placed on the plate and conc. was rotated at $10 \mathrm{rpm}$.

\section{- $\quad$ Stability studies}

To access the drug and formulation stability, the stability studies were carried out as per ICH guidelines. The gel filled in collapsible tube and kept in humidity chamber maintained at $40^{\circ} \mathrm{C} \pm 2{ }^{\circ} \mathrm{C}$ and $75 \pm 5 \% \mathrm{RH}$ for a period of 6 months. Samples were withdrawn at time intervals of 0,3 and 6 months evaluated for its physical appearance, consistency, $\mathrm{pH}$, viscosity.

\section{RESULTS AND DISCUSSION}

\section{PREFORMULATION STUDIES}

\section{Preformulation studies of Havan ash}

\section{- Physical description and organoleptic properties}

The physical description and organoleptic properties of Havan ash includes colour, odour, smell, taste data is given in table no. 4. The particle size of Havan ash is not more than $125 \mu$.

Table 4: Physical description and organoleptic properties

\begin{tabular}{|c|c|}
\hline Colour & Grey \\
\hline Odour & Good, Ambrosial \\
\hline Smell & aromatic \\
\hline Taste & Good \\
\hline
\end{tabular}


- Determination of $\mathrm{pH}$, Acid Insoluble Ash, Watersoluble ash

The $\mathrm{pH}$, Acid insoluble ash, Water insoluble ash is given in table no. 5

Table 5: Shown pH, Acid Insoluble Ash, Water-soluble ash value

\begin{tabular}{|c|c|c|}
\hline $\mathbf{p H}$ & $\begin{array}{c}\text { Acid } \\
\text { Insoluble Ash }\end{array}$ & $\begin{array}{c}\text { Water- } \\
\text { soluble } \text { ash }\end{array}$ \\
\hline 9.2 & 0.15 & 0.03 \\
\hline
\end{tabular}

\section{- IR Spectroscopy}

The IR spectroscopy of Havan ash is given in fig 6 and describe about its peaks in Table no. 6
Table 6: Peak Table of Havan Ash

\begin{tabular}{|c|c|}
\hline Peaks & Functional group \\
\hline $2873(3000-2840)$ & C-H \\
\hline 1798 & C=O \\
\hline 1606 & C=H \\
\hline 1460 & C-H BENDING \\
\hline 1410 & O-H BENDING \\
\hline 1287 & C-O STRECHING \\
\hline 1066 & S=O \\
\hline 989 & C=C \\
\hline 876 & C-H \\
\hline
\end{tabular}

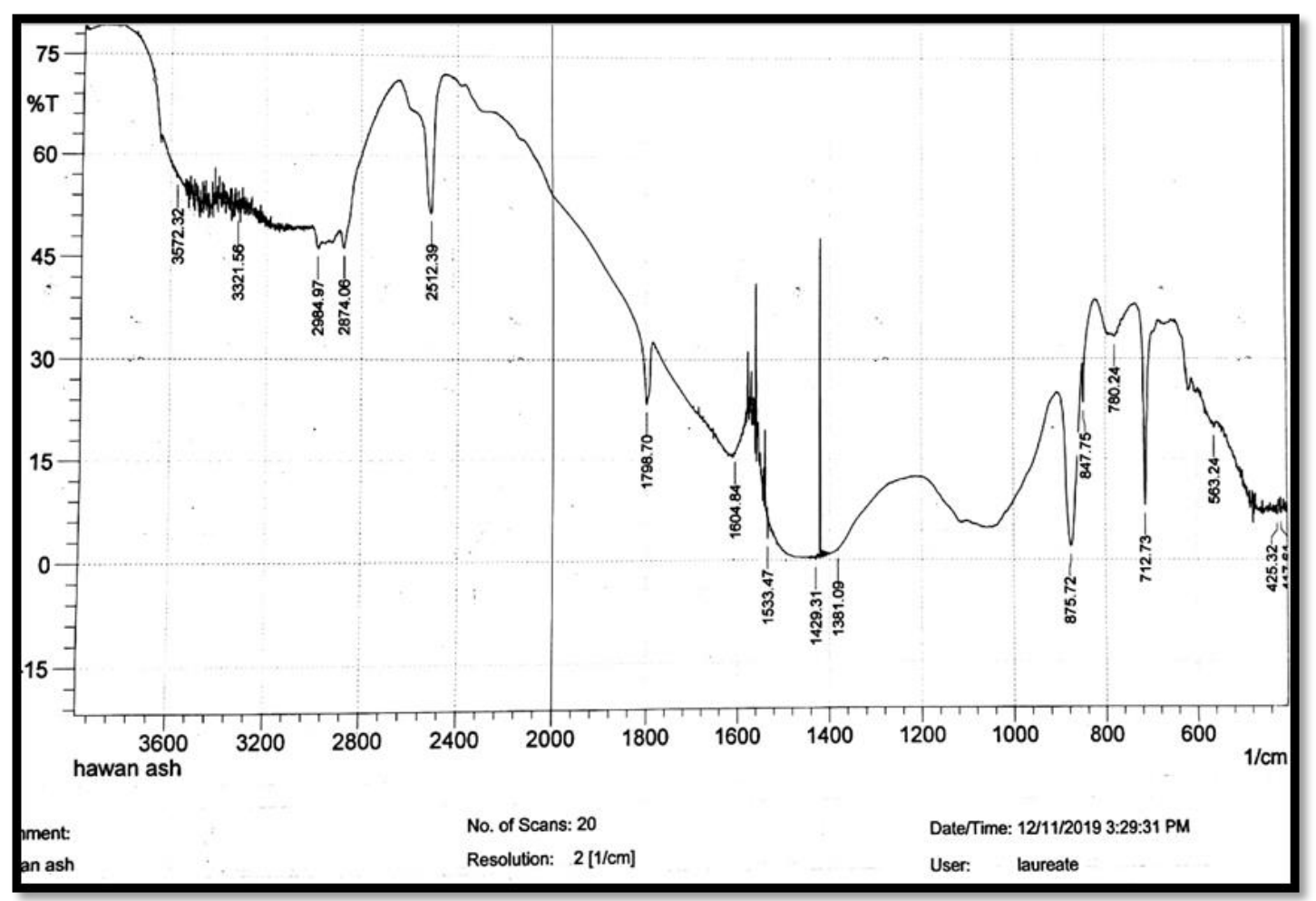

Figure 6: IR of Havan ash 


\section{- Identification test (presence of $\mathrm{Zn}, \mathrm{Na}, \mathrm{K}, \mathrm{Fe}, \mathrm{Ca}, \mathrm{Mg}$, $\mathrm{Al}$ etc. depends upon ingredients)}

The identification of lead, Magnesium, Sulphate, Zinc, Ferrous, Aluminium, Calcium, Sodium and Potassium was performed. The result is given in Table no. 7 .

Table 7: Identification test

\begin{tabular}{|c|c|c|c|}
\hline S.N. & Experiment & Observation & Result \\
\hline 1. & $\begin{array}{l}\text { Dissolve } 50 \mathrm{~g} \text { of the substance under examination in } \mathrm{ml} \text { of dilute acetic acid or use } \\
1 \mathrm{ml} \text { of the prescribed solution. Add } 10 \mathrm{ml} \text { water and } 0.2 \mathrm{ml} \text { of } 1 \mathrm{M} \text { potassium } \\
\text { iodine, a yellow precipitate is formed. Heat to boiling for } 1 \text { or } 2 \text { minutes and allow } \\
\text { cooling, the precipitate is reformed as glistening yellow plates. }\end{array}$ & $\begin{array}{l}\text { Lead is } \\
\text { present. }\end{array}$ & $\begin{array}{l}\text { Lead is not } \\
\text { present. }\end{array}$ \\
\hline 2. & $\begin{array}{l}\text { To } 0.5 \mathrm{ml} \text { of a neutral or slightly acid solution of the substance under examination } \\
\text { add } 0.2 \mathrm{ml} \text { of a } 0.1 \text { per cent } \mathrm{w} / \mathrm{v} \text { solution of titan yellow and } 0.5 \mathrm{ml} \text { of } 0.1 \mathrm{M} \\
\text { sodium hydroxide, A bright red turbidity developed which gradually settles to } \\
\text { give a bright red precipitate. }\end{array}$ & $\begin{array}{l}\text { Magnesium } \\
\text { is present. }\end{array}$ & $\begin{array}{l}\text { Magnesium is } \\
\text { present. }\end{array}$ \\
\hline 3. & $\begin{array}{l}\text { Dissolve } 50 \mathrm{mg} \text { of substance under examination in } 5 \mathrm{ml} \text { of water or } 5 \mathrm{ml} \text { of } \\
\text { prescribed solution then add } 1 \mathrm{ml} \text { of dilute } \mathrm{HCl} \text { and } 1 \mathrm{ml} \text { of barium chloride } \\
\text { solution white precipitate formed. }\end{array}$ & $\begin{array}{l}\text { Sulphate is } \\
\text { present. }\end{array}$ & $\begin{array}{l}\text { Sulphate is } \\
\text { present. }\end{array}$ \\
\hline 4. & $\begin{array}{l}\text { Dissolve } 0.1 \mathrm{~g} \text { of the substance in } 5 \mathrm{ml} \text { of water add } 0.2 \mathrm{ml} \text { of } \mathrm{NaOH} \text { solution a } \\
\text { white ppt are produce add a further } 2 \mathrm{ml} \text { of } \mathrm{NaOH} \text { solution and ppt solved the add } \\
10 \mathrm{ml} \text { of ammonium chloride solution the solution remains clear and add } 0.1 \mathrm{ml} \text { of } \\
\text { sodium sulphate solution. A flocculent, white ppt is produce. }\end{array}$ & $\begin{array}{l}\text { Zinc is } \\
\text { present. }\end{array}$ & $\begin{array}{l}\text { Zinc is } \\
\text { present. }\end{array}$ \\
\hline 5. & $\begin{array}{l}\text { Dissolve a quantity of the substance under examination containing about } 10 \mathrm{mg} \text { of } \\
\text { iron in } 2 \mathrm{ml} \text { of water or use } 2 \mathrm{ml} \text { of the prescribed solution. Add } 2 \mathrm{ml} \mathrm{of} \mathrm{H}_{2} \mathrm{SO}_{4} \text { and } 1 \\
\mathrm{ml} \text { of } 0.1 \% \mathrm{w} / \mathrm{v} \text { solution of } 1-10 \text { phenanthroline; an intense red colour which is } \\
\text { discharge by addition of a slight excess of } 0.1 \mathrm{M} \text { ceric ammonium sulphate is } \\
\text { produced. }\end{array}$ & $\begin{array}{l}\text { Ferrous salt } \\
\text { is present. }\end{array}$ & $\begin{array}{l}\text { Ferrous salt is } \\
\text { present. }\end{array}$ \\
\hline 7. & $\begin{array}{l}\text { Dissolve } 20 \mathrm{mg} \text { of the substance under examination in } 5 \mathrm{ml} \text { of } 5 \text { Macetic acid or } \\
\text { add } 1 \mathrm{ml} \text { of glacial acetic acid to } 5 \mathrm{ml} \text { of the prescribed solution. Add } 0.5 \mathrm{ml} \text { of } \\
\text { potassium ferrocyanide solution, the solution remains clear. Add about } 50 \mathrm{mg} \text { of } \\
\text { on with an ammonium chloride; a white, crystalline precipitate is formed. }\end{array}$ & $\begin{array}{l}\text { Calcium is } \\
\text { present }\end{array}$ & $\begin{array}{l}\text { Calcium is } \\
\text { present }\end{array}$ \\
\hline 8. & $\begin{array}{l}\text { Dissolve about } 20 \mathrm{mg} \text { of the substance under examination in } 2 \mathrm{ml} \text { of water or use } \\
2 \mathrm{ml} \text { of the prescribed solution, add about } 0.5 \mathrm{ml} \text { of } 2 \mathrm{M} \text { hydrochloric acid and } \\
\text { about } 0.5 \mathrm{ml} \text { of thioacetamide reagent; no precipitate is produced. Add dropwise } \\
2 \mathrm{M} \text { sodium hydroxide; a gelatinous white precipitate is produced which } \\
\text { redissolves on addition of further } 2 \mathrm{M} \text { sodium hydroxide. Gradually add } \\
\text { ammonium chloride solution; the gelatinous white precipitate reappears. }\end{array}$ & $\begin{array}{l}\text { Aluminium } \\
\text { is present }\end{array}$ & $\begin{array}{l}\text { Aluminium } \\
\text { present }\end{array}$ \\
\hline 9. & Flame photometry & $\begin{array}{l}\text { Presence of } \\
\mathrm{Na} \text { and } \mathrm{k}\end{array}$ & $\begin{array}{l}\mathrm{Na} \text { and } \mathrm{K} \text { is } \\
\text { present. }\end{array}$ \\
\hline
\end{tabular}

\section{- Rheological study}

The rheological study of Havan ash includes bulk density, tap density, Carr's index, Hausner's ratio and angle of repose. Data of rheological study is given in Table no. 8 and 9.

Table 8: rheological study

\begin{tabular}{|c|c|c|c|c|c|}
\hline Sr. no & Bulk density & Tap density & Carr's index & Hausner's ratio & Flow properties \\
\hline 1. & 0.714 & 0.806 & 11.41 & 1.12 & Good \\
\hline 2. & 0.720 & 0.803 & 10.33 & 1.11 & Good \\
\hline 3. & 0.714 & 0.806 & 11.41 & 1.12 & Good \\
\hline
\end{tabular}

Table 9: Angle of repose

\begin{tabular}{|c|c|c|}
\hline Sr. no & Angle of repose & Properties \\
\hline 1. & $40.4^{0}$ & Fair \\
\hline 2. & $39.7^{0}$ & Fair \\
\hline 3. & $40^{0}$ & Fair \\
\hline
\end{tabular}




\section{Quantitative Analysis}

The quantitative analysis of Zinc and Magnesium is done by Atomic Absorption Spectroscopy shown in table no. 10 and the quantitative analysis of Sulphur is done by titration shown in table no. 10.

Table 10: Quantitative Analysis of Zinc, Magnesium, Sulphur

\begin{tabular}{|c|c|c|}
\hline Protocol & \multicolumn{2}{|c|}{ AAS, Titration } \\
\hline Description & Specification & Observation \\
\hline Test Parameters & Not Specified & $182.6 \mathrm{ppm}$ \\
\hline Zinc & Not Specified & $52.6 \mathrm{ppm}$ \\
\hline Magnesium & Not Specified & $2.36 \%$ \\
\hline Sulphur & & \\
\hline
\end{tabular}

\section{Optimization of Microsponges}

\section{- $\quad$ Particle size analysis of Microsponges}

The data of Particle size analysis of Microsponges is given in Table no. 11

Table 11: Particle size analysis of Microsponges

\begin{tabular}{|c|c|c|}
\hline Sr.no. & Formulation code & Particle size $(\mu \mathrm{m})($ mean \pm S.D) \\
\hline 1. & MSF1 & $42.4 \pm 1.23$ \\
\hline 2. & MSF2 & $40.7 \pm 1.54$ \\
\hline 3. & MSF3 & $38.5 \pm 1.26$ \\
\hline 4. & MSF4 & $31.3 \pm 1.25$ \\
\hline 5. & MSF5 & $37.9 \pm 1.19$ \\
\hline 6. & MSF6 & $42.4 \pm 1.23$ \\
\hline
\end{tabular}

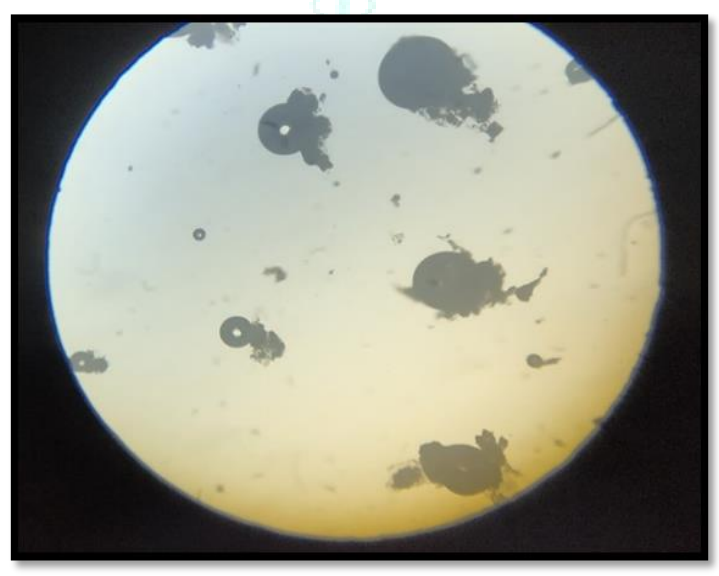

Figure 7: Microsponges under microscope of formulationMSF5

\section{- Percentage yield}

The data of Production yield (\%) or Percentage yield of Microsponges is given in Table no. 12

Table 12: Table of Production yield (\%)

\begin{tabular}{|c|c|c|}
\hline Sr. No. & Formulation code & Production yield (\%) \\
\hline 1. & MSF1 & 82.4 \\
\hline 2. & MSF2 & 85 \\
\hline 3. & MSF3 & 87 \\
\hline 4. & MSF4 & 88.7 \\
\hline 5. & MSF5 & 91.2 \\
\hline 6. & MSF6 & 86 \\
\hline
\end{tabular}




\subsection{Evaluation of Gel Base}

The results of evaluation of gel base were shown in Table no. 13. The colour of all the formulations was found to be turbid white. All the formulations were stable and has a desired consistency for all the gels. The viscosity and spreadabilty of the formulations increased with increase in concentration of carbopol 934. The given parameters must be controlled in skin gels included $\mathrm{pH}$ (4-9). The $\mathrm{pH}$ of all the formulations was within the acceptable range. Human skin is covered with an acid mantle having an acidic $\mathrm{pH}$ but due to frequent washing and use of soap the acidity is lost and hence to normalize the skin, gels used should have an acidic range. Considering all the physicochemical parameters, G2 was selected for further loading of microsponges.

Table 13: Evaluation of Gel Base

\begin{tabular}{|c|c|c|c|c|}
\hline Sr.No. & Parameters & G1 & G2 & G3 \\
\hline 1. & Appearance & Turbid white & Turbid white & Turbid white \\
\hline 2. & Consistency & Good & Good & Good \\
\hline 3. & Grittiness & - ve & -ve & -ve \\
\hline 4. & $\mathrm{pH}$ & $5.2 \pm 0.047$ & $5.5 \pm 0.019$ & $5.8 \pm 0.023$ \\
\hline 5. & $\begin{array}{c}\text { Spreadabilty } \\
\text { (g.cm/sec) }\end{array}$ & $9.6 \pm 1.005$ & $9.8 \pm 1.002$ & $10.5 \pm 1.004$ \\
\hline 6. & Viscosity (cps) & $16120 \pm 50.13$ & $18191 \pm 69.21$ & $21532 \pm 55.37$ \\
\hline
\end{tabular}

\section{Evaluation of Havan Ash Microsponges Loaded Gel}

\section{- Psychometric Evaluation on the Basis of Hedonic Scale}

The data of Psychometric Evaluation On the Basis of Hedonic Scale is given in table no. 14

Table 14: Psychometric Evaluation On the Basis of Hedonic Scale

\begin{tabular}{|c|c|c|c|c|c|}
\hline Sr.No. & $\begin{array}{c}\text { Psychometric } \\
\text { parameters }\end{array}$ & F1 & F2 & F3 & F4 \\
\hline 1. & Colour & 6 & 6 & 8 & 5 \\
\hline 2. & Odour & 7 & 6 & 8 & 6 \\
\hline 3. & Texture & 7 & 6 & 8 & 6 \\
\hline 4. & Wetness & 6 & 7 & 8 & 7 \\
\hline 5. & Gloss & 5 & 6 & 9 & 7 \\
\hline 6. & Stickiness & 7 & 6 & 9 & 6 \\
\hline 7. & Slipperiness & 6 & 7 & 9 & 7 \\
\hline 8. & Firmness & 8 & 7 & 9 & 6 \\
\hline 9. & Appearance & 8 & 7 & 8 & 6 \\
\hline 10. & Rub-out & 7 & 6 & 9 & 7 \\
\hline 11. & After feel effect & 6 & 7 & 9 & 8 \\
\hline 12. & Pick- up & 7 & 7 & 9 & \\
\hline
\end{tabular}

\section{- Evaluation of Havan Ash Microsponges Loaded Gel}

The evaluation of Havan ash Microsponges loaded gel is done by different parameter. The parameters are Appearance, Consistency, Grittiness, homogeneity, wash ability, $\mathrm{pH}$, Spreadabilty, Viscosity. The data of these all parameter in given in Table no. 15

Table 15: Evaluation of Havan Ash Microsponges Loaded Gel

\begin{tabular}{|c|c|c|c|c|c|}
\hline Sr.No. & Parameters & F1 & F2 & F3 & F4 \\
\hline 1. & Appearance & Silver & Silver & Silver & silver \\
\hline 2. & Consistency & Good & Good & Very good & Residue remaining \\
\hline 3. & Grittiness & -ve & -ve & -ve & -ve \\
\hline 4. & Homogeneity & Poor & Good & Good & goor \\
\hline 5. & wash ability & Poor & Good & Very good & 6.9 \\
\hline 6. & pH & 7.2 & 6.5 & 6.3 & $13.5 \pm 0.85$ \\
\hline 7. & $\begin{array}{c}\text { Spreadabilty } \\
\text { (g.cm/sec) }\end{array}$ & $14.3 \pm 1.03$ & $13.9 \pm 0.98$ & $14.4 \pm 0.777$ & $17642 \pm 69.37$ \\
\hline 8. & Viscosity (cps) & $18253 \pm 52.41$ & $18251 \pm 50.12$ & $18251 \pm 50.12$ & \\
\hline
\end{tabular}




\section{- $\quad$ Stability studies}

The prepared gel formulations (F3) were found to be stable upon storage for 6 months, no change was observed in their physical appearance, $\mathrm{pH}$, viscosity, consistency. The result of stability study was shown in Table 16.

Table 16: Stability data of gel at 0, 3 and 6 month

\begin{tabular}{|c|c|c|c|}
\hline Parameters & For 0 month & For 3 month & For 6 month \\
\hline Physical Appearance & Silver & Silver & Silver \\
\hline Consistency & Good & Good & 6.2 \\
\hline $\mathrm{pH}$ & 6.3 & 6.3 & $18251 \pm 50.12$ \\
\hline Viscosity (cps) & $18251 \pm 50.12$ & $18251 \pm 50.12$ & Good \\
\hline
\end{tabular}

\section{CONCLUSION}

Acne vulgaris remains a common condition in industrialized societies, with many mainstream treatment options available. All these treatments carry risks, and none is completely satisfactory. Natural alternatives are gaining greater research support and have much to offer clinically. A wide range of synthetic therapeutic agents have also been reported to cause acne as their adverse effect. In present Hypothesis we have planned to incorporate the herbal Inorganic and Organic actives in the form of Hawan ash. The present hypothesis is designed to explore such Natural and traditionally tested active ingredient which act as antibacterial and help to treat acne for better safer natural treatment. As the different elements (like $\mathrm{Zn}, \mathrm{Fe}, \mathrm{Ca}, \mathrm{Mg}, \mathrm{Na}, \mathrm{k}$ $\mathrm{Mn})$ are present in Havan ash which are help to treat acne such as Topical zinc alone as well as in combination with other agents is effective perhaps because of its antiinflammatory activity and ability to reduce $P$. acnes counts by inhibition of P.acnes lipases and free fatty acid levels. Another proposed mechanism for the benefit of zinc in acne is suppression of sebum production by its anti-androgenic activity. Magnesium lowers cortisol production, thereby potentially helping to reduce acne by stabilising hormonal imbalances in the body. As a topical acne treatment, sulphur works similarly to benzoyl peroxide and salicylic acid. Sulphur kills the P. acnes bacteria, unclogs blocked pores and keeps them clear, and reduces inflammation.

In the preformulation studies of Havan ash include Physical description and organoleptic properties, pH, Acid Insoluble Ash, Water-soluble ash, IR Spectroscopy, Identification test, Rheological study, Atomic Absorption Spectroscopy is also carried out.

Quasi-emulsion solvent diffusion is now days the preferred method to prepare porous microparticles. Quasi emulsion solvent diffusion method is simple, less time consuming and involves use of safer ingredients than free radical polymerization and hence more preferred. Eudragit RS100 microsponges containing Havan ash were successfully prepared by this method. The microsponges were prepared (MSF1-MSF5) by quasi emulsion method and were evaluated for its different parameters which revealed many interesting results for efficient preparation of the microsponges. The formulation MSF5 has better results among 6 formulations. MSF5 have its particle size $(\mu \mathrm{m}) 31.3 \pm 1.25$ and production yield (\%) 91.2 compared to MSF1, MSF2, MSF3, MSF4, MSF6 they have particle size $(\mu \mathrm{m}) 42.4 \pm 1.23,40.7 \pm 1.54,38.5 \pm$ $1.26,38.5 \pm 1.26,37.9 \pm 1.19$ and production yield (\%) 82.4, $85,87,88.7,86$.

Then the Formulation and evaluation of Havan ash microsponges loaded gel is done. The formulation F3 has better results than other F1, F2, F4 formulations. F3 have its appearance silver colour, consistency very good, Grittiness ve, homogeneity good, wash ability very good, $\mathrm{pH}$ 6.3, Spreadabilty (g.cm/sec) $14.4 \pm 0.77$ 7and viscosity (cps) $18251 \pm 50.12$, have good result on psychometric analysis. Stabilities studies were conducted for the prepared Microsponge loaded gel formulation as per guidelines for a period of 6 months which showed that formulation (F1-F3) were observed stable, while F4 were found unstable due to change in its physical appearance, $\mathrm{pH}$, viscosity, consistency. All these parameters are in optimized range for preparing a controlled release dosage form so showing itself as an optimised formulation in this research work. With the revealed results by different evaluation parameters, it is concluded that microsponges drug delivery system has become highly competitive and rapidly evolving technology and more research are carrying out to optimize costeffectiveness and efficacy of the therapy.

\section{REFERENCES}

1. Pathirana W, Abhayawardhana P, Kariyawasam H, Ratnasooriya WD. Transcranial Route of Brain Targeted Delivery of Methadone in Oil. Indian J Pharm Sci. 2009; 71:264-269.

2. Scorer CA. Preclinical and Clinical Challenges in the Development of Disease-Modifying Therapies for Alzheimer's Disease. Drug Discover Today. 2001; 6:1207-1219.

3. Blennow K, De Leon MJ, Zetterberg H. Alzheimer's Disease. Lancet. 2006; 368:387-403.

4. Tripathi KD. Essentials of Medical Pharmacology. New Delhi: JP Brothers Medical Published. 2010; 123-126.

5. Bansal P, Kaur R, Gupta V, Kumar S And Kaur RP. Is There Any Scientific Basis of Havanto be Used in EpilepsyPrevention/Cure? 2015 Dec; 5(2):33-45.

6. Rgyan, Hindu Havan - An Ancient Fire Ritual. November 10, 2017.

7. Garg S, Kndarapu R, Kannan V. Pharma. Tech. 2003; 27(2):74.

8. Katsambas A, Papakonstantiou A. Acne: Systemic Treatment. Clin. Dermatol. 2004; 412-418.

9. Nacht S, Kantz M. The Microsponge: A Novel Topical Programmable Delivery System. 1992; 42:299-325.

10. Patel G, Patel JK. Use of A Microsponge in Drug Delivery Systems. IJRPC. 2012; 2(2):237-244

11. Vyas SP, Khar RK. Targeted and Controlled Drug Delivery-Novel Carrier System: New Delhi: CBS Publication, First Edition. 2002; 453.

12. Parikh BN, Gothi GD, Patel TD, Chavda HV, Patel CN. Microsponge as Novel Topical Drug Delivery System. Journal of Global Pharma Technology. 2010; 2(1):17-29

13. D'souza JI, Harinath NM. Topical Anti-Inflammatory Gels of Fluocinolone Acetonide Entrapped in Eudragit Based Microsponge Delivery System. Research J. Pharm. and Tech 2008; 1(4):502-506.

14. Thappa D, Adityan B, Kumari R. Scoring Systems in Acne Vulgaris. Indian J Dermatol Ve. 2009; 75(3):323-326.

15. Benner N, Sammons D. Overview of the Treatment of Acne Vulgaris, Osteopath Family Physic. 2013; 5(5):185-190.

16. Harper JC. Acne Vulgaris, Emedicine. 2009; 649-659. 
17. Acne. Mayo Clinic Website. Mayoclinic.Org/DiseasesConditions/Acne/Symptoms-Causes/Syc-20368047. Accessed March 11, 2018.

18. Maria Julia Bevilaqua Felippe, In Equine Infectious Diseases (Second Edition). 2014; 2:891-898

19. Models for Acne Drug Discoveries \& Therapeutics. 2018; 12(6):329-340.

20. Jalian HR, Kim J. In Comprehensive Medicinal Chemistry II. 2007; 22-42.

21. Manandhar NP. Plants and People of Nepal Timber Press, Portland, Oregon USA; 2002; 599.

22. Kim SS, Hyun CG, Lee H., Kim JY. In vitro screening of jeju medicinal plant for cosmeceutical material. J. Appl. Biol. Chem. 2007; 50:215-220.

23. Kumar AS, Baboota SP, Agarwal J. Treatment of acne with special emphasis on herbal remedies, Expert. Rev. Dermotol. 2008; 3:111-122.

24. Shweta K, Swarnlata S. Research journal of medicinal plant. 2011; 5(6):650-669.
25. Osmani RA, Aloorkar NH. Microsponges Based Drug Delivery System for Augmented Gastroparesis Theraphy: Formulation Development and Evaluation. Asian Journal of Pharmaceutical Science. 2015; 10:442-451.

26. Kadam VV, Patel VI, Karpe SM, Kadam VJ. Design, Development and Evaluation of Celecoxib- Loaded Microsponges- Based Topical Gel Formulation. Applied Clinical Research. Clinical Trial and Regulatory Affairs. 2016; 3(1):44-55.

27. Singh R and Jain V. Design and Characterization of Colon Specific Drug Delivery System Containing Paracetamol Microsponges. Arch Pharm Res. 2011; 3(4):733-740.

28. Sharma P. Formulation and Evaluation of Gel-Loaded Microsponges of Roxithromycin for Topical Drug Delivery. IOSR Journal of Pharmacy. 2019; 9(5):14-22.

29. Basha BB, Prakasam K, Divakar G. Formulation and Evaluation of Gel Containing Fluconazole- Antifungal Agent. Int.J.Drug Dev. \& Res. 2011; 3(4):109-128. 